\title{
EFFECT OF SUSTAINED-RELEASE DIAMOX ON THE INTRA-OCULAR PRESSURE IN MAN*
}

\author{
BY \\ S. M. DRANCE AND F. CARR \\ From the Glaucoma Clinic, University Hospital, University of Saskatchewan, Canada $\dagger$
}

DIAMOX and the other carbonic anhydrase inhibitors now form a standard adjunct to the treatment of glaucoma throughout the world, and the literature dealing with these substances is very extensive. In spite of the numerous drugs available, search is continuing for the least toxic and also for one requiring less frequent administration.

The present study was carried out to evaluate the action of sustainedrelease Diamox Sequel (Lederle $\ddagger$ ), produced in a 500-mg. capsule containing $125 \mathrm{mg}$. ordinary acetazolamide and $375 \mathrm{mg}$. sustained-release acetazolamide, and to compare it with a single dose of ordinary acetazolamide which starts to reduce intra-ocular pressure after 30 to 90 minutes and reaches its maximum in 1 to 5 hours, the duration of action being somewhere between 8 and 12 hours (Leydhecker, 1960).

\section{NORMAL EYES}

(A) Investigation.-The action of a single dose of $500 \mathrm{mg}$. Diamox Sequel was studied in ten eyes of six patients. This group consisted of patients who were admitted to the eye department and in whom glaucoma was excluded by diurnal ocular tension curves, tonographic studies, visual fields, and a normal appearance of the optic nervehead. Diurnal ocular tension curves were carried out for $\mathbf{4 8}$ hours, the intra-ocular pressure being taken first at 6 a.m. (on waking) and then at 3-hrly intervals during the day until 10 p.m. The patient was then given a test dose of $500 \mathrm{mg}$. Diamox Sequel and the ocular tension curve was continued for the next 24 hours. The changes in intra-ocular pressure were compared with the pressure before the administration of Diamox at the same time of day.

(B) Results. - In all the ten normal eyes tested a fall in intra-ocular pressure

* Received for publication November 7, 1960.

+ The clinic is supported by Federal-Provincial Grant No. 607-9-160.

\# The sustained-release acetazolamide (Diamox Sequels) was kindly supplied by the Lederle Company of Canada. 695 
took place after the administration of the Diamox Sequel. Fig. 1 shows the mean fall in intra-ocular pressure of the normal eyes at different time intervals after the administration of the drug. It can be seen that the fall began during the first 3 hours, was maximal after 8 hours, and was still well maintained after 24 hours.

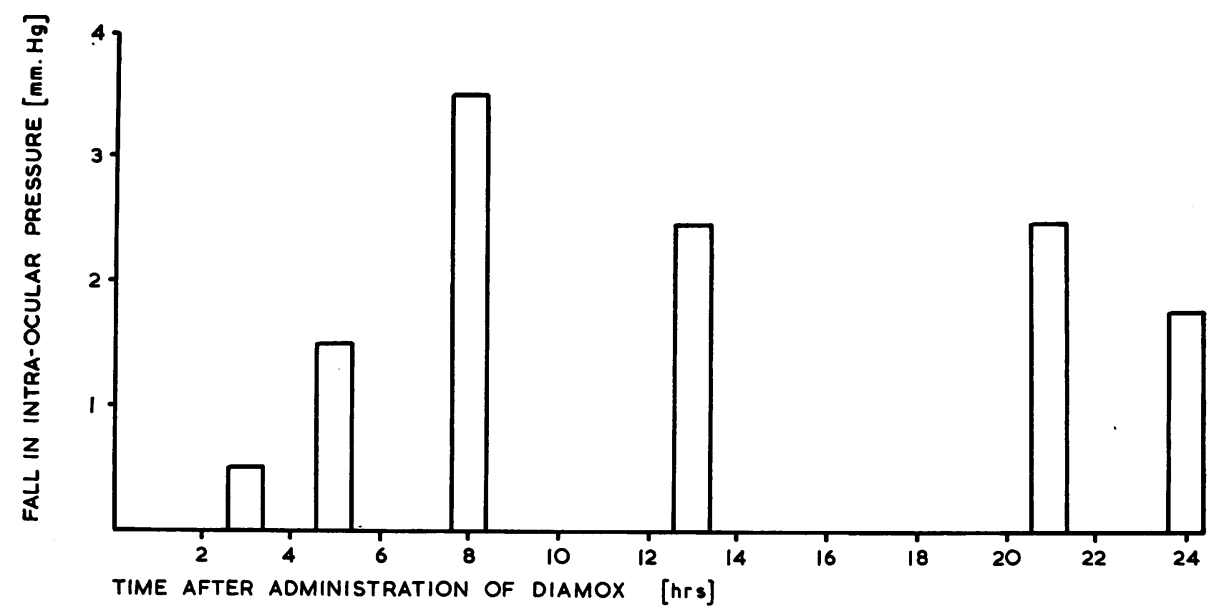

FIG. 1.-Average fall in intra-ocular pressure in ten normal eyes at different time intervals after administration of $500 \mathrm{mg}$. sustained-release acetazolamide.

\section{Glaucomatous Eyes}

(A) Investigation.-The intra-ocular pressure in thirteen eyes in seven patients suffering from chronic simple or secondary glaucoma was checked for phasic diurnal variations for 48 hours before the administration of the Diamox Sequel. Some of these patients were receiving no therapy, and others were inadequately controlled with Pilocarpine or more powerful cholinesterase inhibitors. After the administration of the Diamox Sequel the ocular tension curve was continued for a further 24 hours and the fall in pressure was compared with the levels recorded before the administration of the drug at the same time of day.

38 eyes with chronic simple glaucoma, most of whom were not controlled by miotics, were placed on $500 \mathrm{mg}$. of Diamox Sequel morning and evening. The maximal fall in intra-ocular pressure before and after Diamox therapy was recorded at the same time of day.

(B) Results.-Out of the thirteen eyes of patients in whom only a single Diamox Sequel was administered, eleven showed a fall in intra-ocular pressure and two (both eyes of one patient) showed no fall. The mean fall in intra-ocular pressure of these thirteen eyes is shown in Fig. 2 (opposite), at different time intervals after the administration of the drug. The action of Diamox Sequel started within the first 3 hours, was maximal after 13 hours, and was still maintained after 24 hours. 


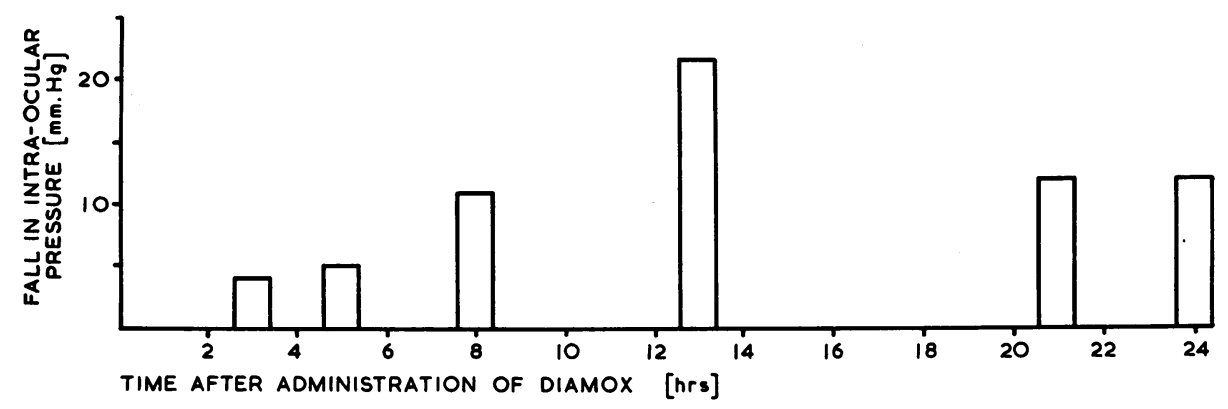

FIG. 2.-Average fall in intra-ocular pressure in thirteen eyes with chronic simple glaucoma, at different time intervals after administration of $500 \mathrm{mg}$. sustained-release acetazolamide.

The results on 38 glaucomatous eyes of the administration of Diamox Sequel twice daily for a few days is shown in Fig. 3. All these eyes showed a fall in intra-ocular pressure ranging from 12 to 62 per cent. of the initial level. Many of these eyes had a normal intra-ocular pressure before the administration of Diamox Sequel and these were the fellow eyes of patients in whom one eye was uncontrolled by miotics while the other eye was adequately controlled by miotics. The Diamox Sequel was administered to lower the intra-ocular pressure of the non-controlled eye. The mean fall in intra-ocular pressure of the 38 eyes after the administration of Diamox for a few days was 36 per cent.

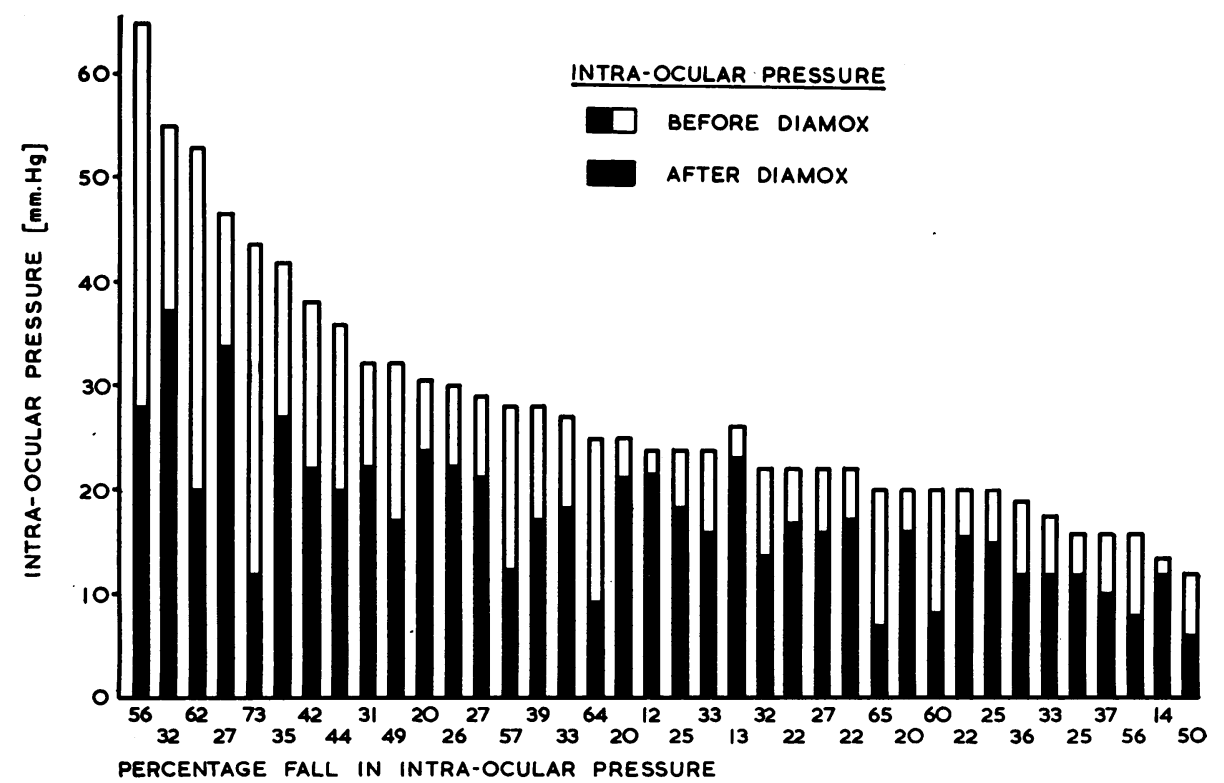

FIG. 3.-Effect on intra-ocular pressure in each of 38 eyes with chronic simple glaucoma of $500 \mathrm{mg}$. sustained-release acetazolamide twice daily. Pressure changes shown in $\mathrm{mm}$. $\mathrm{Hg}$, and expressed as a percentage fall in the initial intra-ocular pressure. 
(C) Side-Effects.-The side-effects of Diamox Sequel in a dosage of $500 \mathrm{mg}$. twice daily were minimal, and amounted to a paraesthesia only. There was some diuresis but this was inconstant. Only one patient complained of gastro-intestinal upset. These side-effects were noted after a very short period therapy, namely a single dose, or therapy for 2 or 3 days. The present study was not intended to report on the side-effects and metabolic effects of Diamox Sequel in long-term therapy, but this will form part of a subsequent communication.

\section{Conclusions}

(1) A single 500-mg. dose of sustained-release Diamox Sequel lowers the intra-ocular pressure in normal and glaucomatous eyes.

(2) The maximal effect of a single dose was seen after 8 to 13 hours, but the effect was still quite pronounced after 24 hours. Ordinary Diamox has its maximal action after 5 hours and ceases to act after 8 to 12 hours.

(3) Sustained release Diamox Sequel given twice daily to patients with chronic simple glaucoma produces a fall in intra-ocular pressure of from 12 to 62 per cent. of the initial level (mean 36 per cent.).

(4) With the dose employed in such a short-term study the side-effects were minimal.

\section{REFERENCE}

LEYDHECKER, W. (1960). “Glaukom”, p. 434. Springer, Berlin. 